\title{
Effect of Cryotherapy on Pain Intensity At Puncture Sites of Arteriovenous Fistula Among Adult Patients Undergoing Hemodialysis at Tanta University Hospital
}

\author{
Afaf Abdelaziz Basal \\ Lecturer of Medical Surgical Nursing, Faculty of Nursing, Tanta University, \\ Kamal Okasha, \\ professor of general Medicine, Faculty of Medicine, Tanta University
}

\begin{abstract}
Background :Patients with end-stage renal disease undergoing hemodialysis are repeatedly exposed to stress and pain from approximately 300 punctures per year to their arteriovenous fistula (AVF). Aim of the study is to investigate effect of cryotherapy on pain intensity at puncture sites of arteriovenous fistula among adult patients undergoing hemodialysis. Subjects and method: Quasi experimental design (pre-post test) was utilized to perform the study. Thirty adult patients undergoing hemodialysis in hemodialysis unit in Tanta University Hospital were enrolled in the study. Patients included in the study were considered at first time as a control group where no cryotherapy used and at second time for three consecutive days of dialysis the same patients considered as a study group when cryotherapy were done. Two tools utilized for the study included: structured interview questionnaire and subjective pain assessment tool (numerical pain rating scale). The results showed that pain from arterial puncture needle was prevalent in $80 \%$ of patients. More than half of patient (57.\%) prefers change the insertion site of needle. There was statistical significant difference before intervention and after intervention by cryotherapy. There was also significant difference in the three consecutive days of intervention. Conclusion: the study concluded that cryotherapy is effective in reducing AV fistula puncture pain of hemodialysis patients. Recommendation: Hemodialysis units should involve cryotherapy for managing needle puncture pain in the routine care for hemodialysis patients.
\end{abstract}

Key wards: cryotherapy, chronic renal failure, hemodialysis, puncture pain 


\section{Introduction}

Chronic renal failure is a major health problem in various parts of the world. The number of patients suffering from end stage renal disease (ESRD) is increasing in both developed and developing countries. Chronic renal failure (CRF) is a devastating medical, social, and economic problem for both patients and their families. ${ }^{(1,2)}$

The most common cause of CRF is diabetes, malignant hypertension and glomerular nephritis. The two major therapies for ESRD patient are dialysis and kidney transplantation. There are two types of dialysis; peritoneal dialysis and hemodialysis. Hemodialysis (HD) is the most common therapeutic method used to treat advanced and permanent renal failure. Hemodialysis is the most frequently used renal replacement therapy with the arteriovenous fistula (AVF) being the gold standard for vascular access in hemodialysis patients ${ }^{(3-4)}$

Patients with end-stage renal disease undergoing hemodialysis are repeatedly exposed to stress and pain from approximately 300 punctures per year to their AVF. Considerable patient discomfort and stress can be associated with the insertion of large-gauge needles into an AVF. Alleviation of this pain might improve their acceptance of the procedure and thus, their quality of life ${ }^{(5-6) .}$

Nurses have a central role in assessing patients' pain and providing pain treatment options; therefore, they are in a position where they can decrease the number of people suffering from pain and the undertreatment of pain. ${ }^{(6)}$. Pain inflicted by the insertion of large cannulae into the AVF is a significant cause of concern for both children and adults on regular HD. Although AVF puncturing causes pain, local anesthesia is not frequently used due to concerns of vasoconstriction, burning sensation, scarring, and infection. ${ }^{(7-8)}$

Kozier, 2008 (9) stated that The complementary therapies are used to relieve the symptoms of pain. These include relaxation technique, visual imagery, cryotherapy, massage, aromatherapy etc. Increasingly complementary therapies are attracting attention in contemporary nursing practice. These interventions are suitable for procedures like injections, venepuncture, 


\section{Tanta Scientific Nursing Journal}

that cause acute transitory pain. Cold application relaxes muscle and muscle contractility, vasoconstriction decreases capillary permeability, decreases blood flow, slows cellular metabolism, decreases pain by slowing nerve conduction rate and blocking nerve impulses, decreases edema by reducing capillary permeability.

Research evidence shows that cutaneous stimulation is an independent nursing intervention that is advocated to minimize pain in patients. The effect of cutaneous stimulation is best explained by the gate control theory. There is evidence that cold signals are transmitted to the spinal cord exclusively by A-delta fibers and not by $\mathrm{C}$ fibers, which may provide a potential method for differentiating among the multiple feedback systems that mediate analgesia. ${ }^{(10-11)}$ Cutaneous interventions such as heat or cold work according to the gate control theory of pain transmission. Stimulation of the skin activates the large diameter nerve fibers and prevents the short diameter nerve fibers from transmitting pain to the brain . Cutaneous stimulation may be applied to the site of pain or other sites distal or proximal to the pain. ${ }^{(12)}$

This study was therefore undertaken to look at the effect of cryotherapy on pain due to arteriovenous fistula puncture in hemodialysis patients, and to correlate the perceived pain with selected variables such as age, sex, duration of AV fistula use, and the educational status of the subjects.

\section{Aim of the study:}

The aim of this study was to investigate the effect of cryotherapy on pain intensity at puncture sites of arteriovenous fistula among adult patients undergoing hemodialysis.

\section{Research Hypothesis:}

Patients used cryotherapy before arteriovenous fistula puncture will have lower pain intensity.

\section{Subjects and Methods}

Design: Quasi experimental design (pre-post test) was utilized to perform the study.

Setting: dialysis units in Tanta University Hospital

\section{Sample:}

Systematic random sample of 30 patients selected from one hundred patients undergoing HD using arteriovenous fistula 
attending three consecutive dialysis session / week. Five patients / day were selected during June and July 2013.

The inclusion criteria were: patient with chronic renal failure undergoing HD using AVF, aged 18-60 years, not having sensitivity to ice or taking topical anesthetic preparation before needle puncture. Exclusion criteria included: inflammation in the fistula, patients having radiation injuries, peripheral vascular diseases, Raynauld's syndrome, connective tissue disorders, diabetic neuropathy, taking topical anesthetic preparation before needle puncture, unconsciousness or disorientation.

\section{Tools of data collection:}

\section{Two tools used for data collection :}

1- Structured interview questionnaires constructed by the researchers after reviewing the relevant literature. It covered the following items: sociodemographic data (age, sex, marital status, level of education,...) ,disease history and duration of fistula.

2- Pain assessment scale The Numeric Rating Scale (NRS-11) is an 11-point from 0 to 10 . It is scale for patient selfreporting of pain. It is for adults and children 10 years old or older. ${ }^{[13]}$ It was used four times as one pre and three time post test.

\begin{tabular}{|c|c|}
\hline Rating & Pain Level \\
\hline 0 & No Pain \\
\hline $1-3$ & Mild Pain \\
\hline $4-6$ & Moderate Pain \\
\hline $7-10$ & Severe \\
\hline
\end{tabular}

\section{Method}

1. An official permission to carry out the study was obtained from responsible authorities in dialysis units at Tanta University Hospital

2. The purpose of the study was explained and made clear to the head of study setting to get their co-operation and acceptance

3. The purpose of the study was explained to the patients and their verbal consent to participate was received

4. Content validity of the tool was checked by ten experts in nursing and medical staff.

5. Reliability was done (Cronbach's Alpha $0.72)$.

6. Pilot study was conducted on five patients to test applicability of the tools. 
The necessary modifications were done accordingly.

7. The researchers collected data by faceto-face interview from the patients on two sessions, each session duration was about 20-25 minutes. Patient's consent, demographic data and patient history data collected in the first session. Also the researchers explained subjective pain assessment tool and how to use cryotherapy for the studied patients in the second section.

8. Pain scoring was done on four consecutive visits ( session) of hemodialysis treatment, without intervention in the first visit and with cryotherapy on the second, third and fourth visit in the studied patients.

9. In the second ,third and fourth session the researchers asked the studied patients to use cold application (ice cubes $2-3 \mathrm{~cm}$ wrapped in gloves on the web between the thumb and index finger of the hand not having the $\mathrm{AV}$ fistula (contralateral arm). The procedure was started ten minutes before venipuncture and continued throughout the puncturing procedure (approximately two minutes) during insertion the needle. The researcher herself performed the ice massage, while another staff member did the AVF cannulation after sterilization. Ice massage done until skin numbness was felt (replacing the frozen ice bag occurred when necessary if ice melting start). (11)

10. Disinfection was done for puncture sites of the AV fistula as usual protocol of sterilization in the center by using betadin swab. After puncture each patient record his feeling of pain according to numerical pain rating scale to the researcher.

11. Scoring system was used to divide pain into four levels as following: score zero means no pain, scores 1-3 mild pain, scores 4-6 moderate pain, scores 7-10 severe pain.

12. Ethical consideration all participants interviewed for explaining the purposes and procedures of the study, and they have the right to withdrawal from the study at any time of the study. Oral consent to participate was assumed. 
Confidentiality and privacy of patient was ascertain

\section{Statistical analysis:}

The collected data were, organized, tabulated and statistically analyzed using statistical package of social studies (SPSS) version 19. For numerical variables, range, mean and standard deviation were calculated. For categorical variables the number and percentages were calculated. The difference between observation before intervention and that at different periods of follow up were tested using Wilcoxon singed ranks test. Pearson's correlation coefficient was calculated to test for association between pain level and other studied numerical and ordinal variables. The level of significance was adopted at $\mathrm{p}<0.05$.

\section{Results}

Table (1): demographic characteristics of the studied patients. In relation to age of the studied patient, the mean age of patients was $49.27 \pm 12.06$ years. High percentage $(73 \%)$ of patients was male and married. The percentages of patients who had primary education, employee and living in rural area were $37 \%, 63 \%$ respectively. Also high percentage of patients $73 \%$ were nonsmoker and more than half $57 \%$ had hypertension as associated disease. Majority of patients 80 $\%$ of patients mentioned arterial needle as the most painful site of needle puncture. The range of the duration of fistula were from 4 month to 11 years. More than half of patient $57 \%$ of patient prefer change the insertion site of needle.

Table (2): Pain level among studied patients in relation to period of follow up: there was statistical significant difference before intervention and after intervention by cryotherapy. There is also significant difference in the three consecutive teaching ways of intervention.

Table (3): Correlation between pain score level, age in years, educational level, duration of disease and shunt

Show no statistical significant negative correlation between age and pain intensity before intervention and first day of uses cryotherapy. There was also non statistical significant negative correlation between duration of shunt and pain intensity before and after uses of cryotherapy. 
Table (1): Demographic characteristics of studied patients

\begin{tabular}{|c|c|c|}
\hline Variables & N0 (30) & $\%$ \\
\hline \multicolumn{3}{|l|}{ Age in years: } \\
\hline$<40$ & 5 & 17 \\
\hline $40-$ & 11 & 37 \\
\hline $50-$ & 10 & 33 \\
\hline $60+$ & 4 & 13 \\
\hline Mean + SD & $49.27+12.06$ & \\
\hline \multicolumn{3}{|l|}{ Gender: } \\
\hline Males & 22 & 73 \\
\hline Females & 8 & 27 \\
\hline \multicolumn{3}{|l|}{ Marital status: } \\
\hline Married & 22 & 73 \\
\hline Divorced & 2 & 7 \\
\hline Widow & 2 & 7 \\
\hline Single & 4 & 13 \\
\hline \multicolumn{3}{|l|}{ Educational level: } \\
\hline Illiterate & 10 & 33 \\
\hline Primary & 11 & 37 \\
\hline Secondary & 8 & 27 \\
\hline University & 1 & 3 \\
\hline \multicolumn{3}{|l|}{ Occupation: } \\
\hline Farmer & 1 & 3 \\
\hline Employee & 19 & 63 \\
\hline House wife & 5 & 17 \\
\hline Retired & 5 & 17 \\
\hline \multicolumn{3}{|l|}{ Residence: } \\
\hline Urban & 8 & 27 \\
\hline Rural & 22 & 73 \\
\hline \multicolumn{3}{|l|}{ Smoking status: } \\
\hline Smoker & 5 & 17 \\
\hline Non smoker & 22 & 73 \\
\hline Ex-smoker & 3 & 10 \\
\hline
\end{tabular}


Table 1 continue

\begin{tabular}{|l|c|c|}
\hline Variables & No (=30) & \% \\
\hline Associated diseases:* & 11 & 37 \\
Diabetes & 17 & 57 \\
Hypertension & 1 & 3 \\
Ischemic heart disease & 5 & 17 \\
Hepatitis C & Range from 4 month to 11 years \\
\hline Duration of fistula & \multicolumn{2}{|c|}{} \\
\hline The most painful site & 24 & 80.0 \\
Arterial & 1 & 3 \\
Venous & 5 & 17 \\
Both & 17 & 57 \\
\hline Prefer to change insertion & \multicolumn{2}{|c|}{} \\
site & \multicolumn{2}{|c|}{} \\
\hline
\end{tabular}

*more than one answer

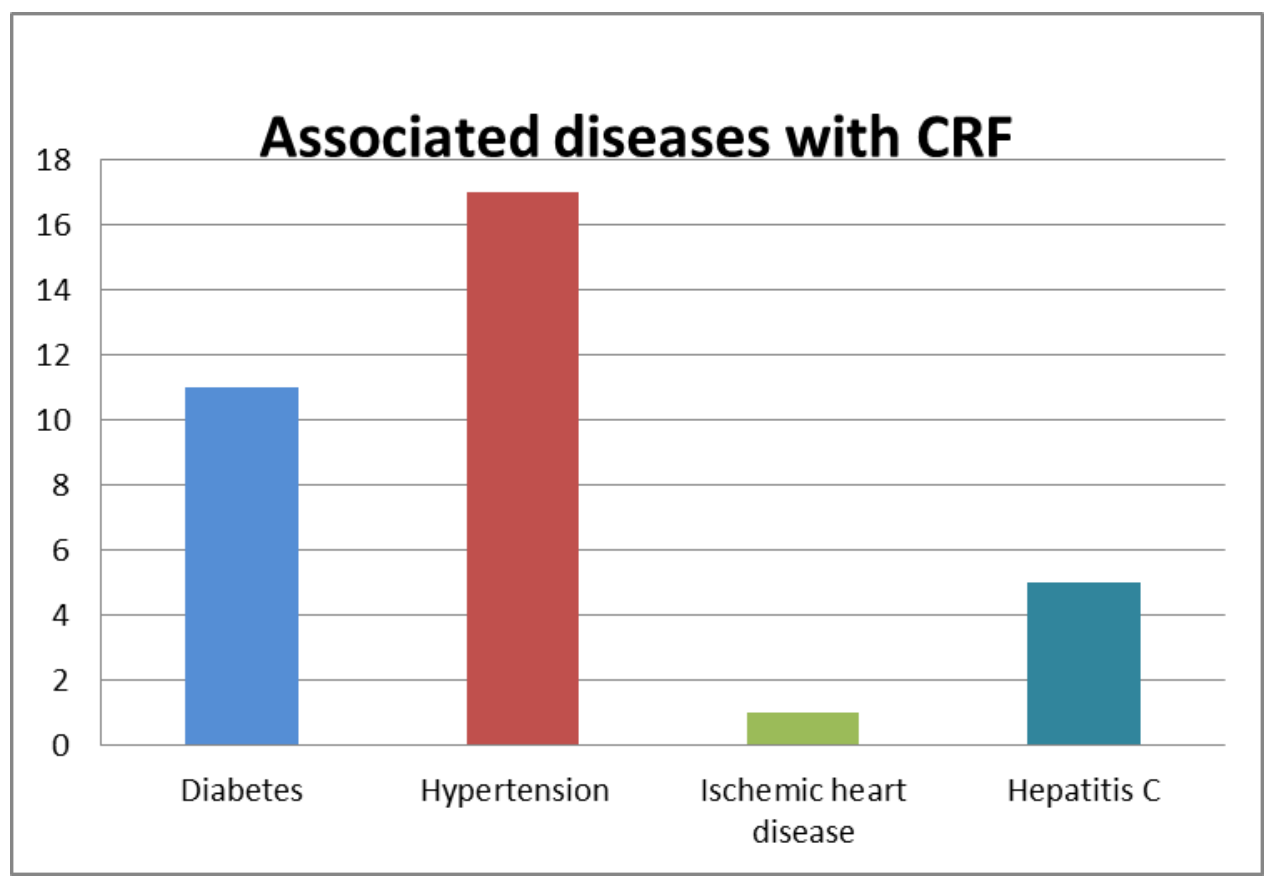

Vol. 5 No. 2 November, 2013 
Table (2): Pain level among studied patients in relation to period of follow up

\begin{tabular}{|c|c|c|c|c|c|c|c|c|}
\hline \multirow{3}{*}{ Pain level } & \multirow{2}{*}{\multicolumn{2}{|c|}{$\begin{array}{l}\text { Before } \\
\text { intervention }\end{array}$}} & \multicolumn{6}{|c|}{ After intervention by cryotherapy } \\
\hline & & & \multicolumn{2}{|c|}{ Visit one } & \multicolumn{2}{|c|}{ Visit two } & \multicolumn{2}{|c|}{ Visit three } \\
\hline & $\mathrm{N}$ & $\%$ & $\mathrm{~N}$ & $\%$ & $\mathrm{~N}$ & $\%$ & $\mathrm{~N}$ & $\%$ \\
\hline No Pain & 0 & 0 & 0 & 0.0 & 10 & 33.3 & 10 & 33.0 \\
\hline Mild Pain & 15 & 50.0 & 19 & 63.3 & 12 & 40.0 & 15 & 50.0 \\
\hline Moderate Pain & 12 & 40.0 & 11 & 36.7 & 8 & 26.7 & 5 & 16.7 \\
\hline Severe Pain & 3 & 10.0 & 0 & 0.0 & 0 & 0 & 0 & 0.0 \\
\hline $\mathrm{Z}$ & & & \multicolumn{2}{|c|}{2.646} & \multicolumn{2}{|c|}{4.472} & \multicolumn{2}{|c|}{4.600} \\
\hline $\mathrm{P}$ & & & \multicolumn{2}{|c|}{$0.008^{*}$} & \multicolumn{2}{|c|}{$0.001 *$} & \multicolumn{2}{|c|}{$0.001 *$} \\
\hline
\end{tabular}

* Statistically significant at $\mathbf{p}<0.05$

Table (3): Correlation between pain score level, age in years and educational level, duration of disease and shunt

\begin{tabular}{|c|l|l|l|l|l|l|l|l|}
\hline \multirow{3}{*}{ Variables } & \multicolumn{9}{|c|}{ Pain level } \\
\cline { 2 - 9 } & \multicolumn{1}{|l|}{$\begin{array}{l}\text { Before } \\
\text { intervention }\end{array}$} & \multicolumn{7}{|c|}{ After intervention } \\
\cline { 2 - 9 } & $\mathrm{R}$ & $\mathrm{P}$ & $\mathrm{R}$ & $\mathrm{P}$ & $\mathrm{R}$ & $\mathrm{P}$ & $\mathrm{R}$ & $\mathrm{p}$ \\
\hline Age in years & -0.067 & 0.752 & -0.319 & 0.086 & 0.113 & 0.551 & 0.107 & 0.574 \\
\hline Educational level & 0.442 & $0.015^{*}$ & 0.262 & 0.162 & 0.341 & 0.065 & 0.250 & 0.182 \\
\hline $\begin{array}{c}\text { Duration of } \\
\text { disease }\end{array}$ & 0.262 & 0.162 & 0.310 & 0.095 & 0.009 & 0.964 & 0.056 & 0.769 \\
\hline duration of shunt & -0.174 & 0.58 & -0.156 & 0.410 & -0.293 & 0.116 & -0.264 & 0.158 \\
\hline
\end{tabular}




\section{Discussion}

Cryotherapy has been accepted for decades as an effective, inexpensive and simple intervention for pain management. It is widely believed that the therapeutic application of cryotherapy leads to a reduction in pain and swelling, but the physiological basis for this effect is still incompletely understood. Pain relief with cold application could be due to many mechanisms including altered nerve conduction velocity $(\mathrm{NCV})$, inhibition of nociceptors, a reduction in muscle spasms and/or a reduction in metabolic enzyme activity levels. ${ }^{(15)}$

In the present study the mean of age of patients were $49.27 \pm 12.06$ years of age. This consistence with Badheeb ${ }^{(16)}$, who found the mean age range of the HD patients, was 42 years. Also, this finding was in line with Jhamb et al ( 2011) ${ }^{(17)}$ \& Bossola et al ( 2009) ${ }^{(18)} \&$ Koyama et al (2010) ${ }^{(19)}$ and Letchmi, et al (2011) ${ }^{(20)}$ who found that most of the sample under age group 40-60 years. The result of this study revealed that high percentage $(73.3 \%)$ of patients was male and married. This consistence with Ali et al., $201{ }^{(21)}$ and the results of El-Sayed and Lutf (22-23) respectively who stated that near three fifth of their studied patients were males and nearly two thirds of them were married. Also, the result constant with Kamal et.al (2001) (24) who recorded that two third of the sample were male and most of the studied subjects were married. The result also disagrees with Bahgat et.al ${ }^{(25)}$ that showed that more than half of their studied subjects were females. Also the finding was in disagreement with Liu (2006) (26) \& Morsch, et al. (2006) ${ }^{(27)}$ and O'Sullivan et al $\left(\mathbf{2 0 0 7}{ }^{(\mathbf{2 8})}\right.$ who reported that most of their sample were female.

In the present study two third of the patients in this study were educated and this in agreement with the study of Ali et al., (21) Results revealed that, above one third of the studied patients had basic education. More over the study of Bahgat et al., $2013{ }^{(25)}$ and Kamal (2001) ${ }^{\text {(24) }}$ who recorded that half of the study sample were educated.

The results revealed that more than half of the studied patient had hypertension. This agreement with the study of El-Sayed (22), who found the common co-morbidity was 
hypertension, diabetes mellitus, followed by cardiovascular disorders. Also this results agreement with Bahgat et al. $2013^{(25)}$ who found half of their sample had hypertension as a cause of end stage renal disease (ESRD) - Also our results are in agreement with findings of Kamal et al. (2001) ${ }^{(24)}$ who found that most of the sample had hypertension as a cause of ESRD.

The results revealed that more than half of the studied patients were employee this constant with Kamal et al. (2001) ${ }^{(24)}$ who found that most of the study sample was employed. But this finding was contradicted with Bahgat et al., $2013{ }^{(25)}$ Liu (2006) ${ }^{(26)}$ who found that most of the sample unemployed and have manual work

Also the results revealed that all of the studied patients undergoing hemodialysis three times weekly, and lasts for 4 hours each session of hemodialysis. This result was accordance with Bahgat et al., $\mathbf{2 0 1 3}^{(25)}$ ,Jhamb et al (2008) ${ }^{(27)} \&$ Fransesca, et al (2012) ${ }^{(28)}$ who reported that most of patients undergoing hemodialysis at least three times a week for four hours each session.

In the present study, subjective pain scores were found to be significantly $(\mathrm{P}=0.001)$ reduced within the experimental group with the application of cryotherapy during three days of intervention. This is in agreement with Sabitha et al., $2008{ }^{(29)}$ who found cryotherapy was to be an effective pain management technique in hemodialysis patient with AVF also consistent with the result of Hasan et al., $2012{ }^{(30)}$ and Mansy et al., (2010) ${ }^{(31)}$, who found that there was statistical significant difference between cold therapy group and control group which means that cold therapy was effective pain management method for decrease pain associated with injection..

Moreover the result of study conducted in patients suffering from acute dental pain was treated with ice massage of the web between the thumb and index finger of the hand on the same side as the painful region. Ice massage decreased the intensity of dental pain in the majority of patients. The authors also found it to be as effective as transcutaneous electric stimulation in reducing lower back pain. ${ }^{(32,33)}$. Walters et al., $2003^{(34)}$ investigated the use of ice massage of the large intestine acupressure energy meridian point (LI4) to reduce labor pain during contractions and showed 
successful reduction in the intensity of labor pains. However, the studies evaluating the effect of cutaneous stimulation on injection and AVF puncture pain have shown conflicting results. Park et al., $1998^{(35)}$ found that cutaneous stimulation decreased intravenous injection pain in chemotherapy patients with a reduction in both the objective and subjective pain scores.

Also the study of Kakoei et al $2013^{(36)}$ showed that cryotherapy can reduce pain severity and symptoms of mucositis in patients with head and neck cancer, undergoing radiotherapy.

The mechanisms involved in the reduction of pain by using cryotherapy can be best explained by the gate control study proposed by Melzac et al.. ${ }^{(32,33)}$

There were non statistical significant correlation between two group control and the studied group in relation to age, duration of shunt and level of education and this constant with Sabitha $2008^{(28)}$ who found that there was non statistical significant correlation between the AV fistula puncture pain scores and variables such as the duration of AV fistula use and the age of the subjects.

Also the results revealed non-significant negative correlation in the studied patient control and both control and experimental patient in relation to duration of the shunt, this may due to coping of the patient with the disease . This constant with Hassan et al $2012^{(30)}$ who found There were obvious negative correlations between duration of disease, dialysis and AVF with subjective pain scores in the study group day 4 (vein site)

\section{Conclusion:}

Cryotherapy is effective in reducing AV fistula puncture pain of hemodialysis patients. There was no correlation with the duration of fistula use (number of punctures undergone), the educational level, or the age of the studied subjects.

\section{Recommendation:}

The study recommended that:

- Hemodialysis units should involve cryotherapy for managing needle puncture pain in the routine care for hemodialysis patients.

- Apply the same study on a larger group of patients with hemodialysis in different area. 


\section{References}

1- Gutirrez and petron G.,Nursing Survival Guide Pathophysiology. $2^{\text {nd }}$ edition USA, 2008; 464.

2- Schilling J, and Holmes H., Nursing process approach to extent care 4th ed . Philadelphia. Lippincot company. 2006; 895- 899 .

3- Smeltzer S, Bare B . Text book of medical surgical nursing. 10th ed . London: Lippincott Williams \& Wilkins Co., 2004 ; 1286, 1326- 35, 1527

4- Khakha DC, Mahajan S, Gupta S. et al., Effect of cryotherapy on arteriovenous fistula puncture-related pain in hemodialysis patients. Indian J Nephrol. 2008; $18: 155-158$

5- Quinn RR, Lamping DL, Lok CE. et al.,The Vascular Access Questionnaire: assessing patient-reported views of vascular access. J $\quad$ Vasc Access2008;9:122-128

6- Crespo Montero R, Rivero Arellano F, Contreras Abad MD. et al. Pain degree and skin damage during arteriovenous fistula puncture. Edtna Erca J. 2004;30:208-212
7- Lynch, M.. Pain as the fifth vital sign. Journal ofIntravenous Nursing, 2001 24, 85-93.

8- Ball LK., Improving arteriovenous fistula cannulation skills. Nephrol Nursing Jr, 2005.;32:6.

9- Kozier, Berman, Synyder, ERab's. Fundamentals of Nursing: Concepts, Process, and Practice. 9th ed. pearson, ,2008;330-332.

10-Bauer M. The final days of traditional beliefs. Chinese Medicine Times 2006;1: 4 .

11-Sabitha P. B., . Khakha,,D, . Mahajan S, Gupta S, . Agarwal M, and Yadav S. L., Effect of cryotherapy on arteriovenous fistula puncture-related pain in hemodialysis patients, indian $\mathbf{J}$ Nephrol. 2008; 18(4): 155-158.

12-Titler, M., \& Rakel, B., Nonpharmacologic treatment of pain. Critical Care Nursing Clinics of North America . 2001; 13(3):221-229.

13-McCaffery, M., \& Beebe, A. Pain: Clinical Manual for Nursing Practice. Baltimore:V.V.MosbyCompany1993;. 68-73 
14- Ferreira-Valente M.A , PAIN, 2011; 152, 2399-2404, www.el sevier .com/ locate/pain.

15- Amin A Algafly and Keith P George , The effect of cryotherapy on nerve conduction velocity, pain threshold and pain tolerance,, $\mathrm{Br} \mathrm{J}$ Sports Med. June2007; 41(6): 365-369.

16-Badheeb M. A. , Causes of chronic renal failure in hemodialysis unit: a single center experience in Yemen. Collage of Medicine, University of Adhramout for Science and Technology. Saudi J Kidney Dis Transplant. 2006; 17 (1), PP. 66-69.

17-Jhamb M, Pike F, Ramer S, Argyropoulos C, Steel J, Dew M. Impact of Fatigue on Outcomes in the Hemodialysis (HEMO) Study. American Journal of Nephrology, 2011;33(6): 515-523.

18-Bossola M, Luciani G \& Tazza L. Fatigue and its correlates in chronic hemodialysis patients. Blood Purification2009; 28(3): 245-252.

19- Koyama H, Fukuda S, Shoji T, Inaba M, Tsujimoto Y, Tabata T. ,Fatigue is a predictor for cardiovascular outcomes in patients undergoing hemodialysis. Clinical Journal of the American Society of Nephrology, 2010; 5(4): 659666.

20-Letchmi S , Das S, Halim H, Zakariah F, Hassan H, Mat S. ,Fatigue experienced by patients receiving maintenance dialysis in hemodialysis units. Nurs Health Science, 2011;13(1): 60-64.

21- Ali .H, Elsebai. N, Ramadan F.; Salam . $\mathrm{W}$ and Abdelhady T., Impact of Teaching Guidelines on Quality of Life for Hemodialysis Patients, Nature and Science, 2011;9(8):21

22-El-Sayed M. M. : Nurses Role in Managing Complications of Patients on Hemodialysis. M.Sc.N Thesis, Faculty of Nursing, Ain Shams University. 2007; 147-148, 154 .

23-Lutf A. Assessment of Self-Care Practices Among Patients on Maintenance Hemodialysis. M.Sc.N Thesis, Faculty of Nursing, Alexandria University. 2004; 135,139.

24- Kamal A., Fuad K., Al Bediwi M, Quality of life of patients with end stage renal disease. Published Master Thesis 
Faculty of Nursing. University of Ain shams. 2001.

25-Bahgat . Z., Elazay H., Bahgat R., , The Effect Of Fatigue On Daily Living Activities For Adults Undergoing Hemodialysis, published Master Thesis, Faculty of Nursing, Tanta university, 2013.

26- Liu H., Fatigue and associated factors in hemodialysis patients in Taiwan. Research in Nursing and Health, 2006; $29(1) ; 40-50$.

27- Jhamb M, Weisbord S, Steel J \& Unruh M., Fatigue in patients receiving maintenance dialysis: a review of definitions, measures, and contributing factors. American Journal of Kidney Diseases, 2008; 52(2), 353-365.

28- Fransesca T, Jianio Z, Angelo K, Peter $\mathrm{K}$, Rajiava S, Jeorgen B ,Fridrich $\mathrm{p}$ ,Takashi A., Duration of hemodialysis treatment, Oxford Journal of Kidney Diseases, 2012 , 50(2) ; 269.

29-Sabitha, P.B., Khakha, D.C., Mahajan, S., Gupta, S., Agarwal, M., and Yadav, S.L. . Effect of cryotherapy on arteriovenous fistula puncture-related pain in hemodialysis patients. Indian $\mathrm{J}$ Nephrol, 2008;18:155-8.

30-Hassan A, Darwish A ; El-Samman G., and Fadel F., The impact of cryotherapy on pain intensity at puncture sites of arteriovenous fistula among children undergoing hemodialysis. J Am Sci; 2012; 8(12):1490-1500.

31-Mansy, G. E., Zaher, S.R., Waziry, O.G. and Eshak, E.G. The effect of two non-pharmacologic pain management methods on pain-associated with intramuscular injection among rheumatic children. Alexandria Journal of Pediatric, 2010, 24. 135-142.

32- Melzack R, Guite S, Gonshor A., Relief of dental pain by ice massage of the hand. Can Med Assoc J 1980;122:189-91.

33- Melzack R, Jeans ME, Stratford JG, Monks RC., Ice massage and transcutaneous electrical stimulation: Comparison of treatment for low-back pain. Pain ,1980; 9:209-17

34- Waters BL, Raisler J., Ice massage for the reduction of labor pain. J Midwifery 


\section{Tanta Scientific Nursing Journal}

Women's Health, 2003, 48:317-21.

35-Park JS., The effect of cutaneous stimulation and distraction on IV injection pain of chemotherapy patients. J Korean Acad Nurs. 1998,28:303-18.

36- Kakoei S , Ghassemi A, Nakhaee N, Effect of cryotherapy on oral mucositis in patients with head and neck cancers receiving radiotherapy, International Journal of Radiation Research, April 2013;11(2):117-120. 